\title{
Effectiveness of the retreatment of patients with multibacillary leprosy and episodes of erythema nodosum leprosum and/or persistent neuritis: a single-center experience*
}

\author{
Joel Carlos Lastória ${ }^{1}$ \\ Maria Stella de Mello Ayres Putinatti ${ }^{1}$
}

\author{
Thaís Sampaio Corrêa de Almeida ${ }^{2}$ \\ Carlos Roberto Padovani ${ }^{3}$
}

DOI: http:/ / dx.doi.org/10.1590/abd1806-4841.20185387

\begin{abstract}
BACKGROUND: Erythema nodosum leprosum may appear before, during or after treatment of leprosy and is one of the main factors for nerve damage in patients. When it occurs or continues to occur after treatment, it may indicate disease recurrence and a new treatment may be instituted again.

ОвјЕСтіVE: To evaluate the retreatment of patients with multibacillary leprosy who underwent standard treatment with multidrug therapy, but developed or continued to present reactions of erythema nodosum leprosum and/or neuritis 3-5 years after its end. METHOD: For this objective, a new treatment was performed in 29 patients with multibacillary leprosy who maintained episodes of erythema nodosum and/or neuritis 3-5 years after conventional treatment.

RESULTS: In general, we observed that $27(93.10 \%)$ had no more new episodes after a follow up period of eight months to five years. In five of these patients the reason for the retreatment was the occurrence of difficult-to-control neuritis, and that has ceased to occur in all of them.

STUDY LIMITATIONS: Small number of patients.

CONCLUSION: IN the cases observed, retreatment was an effective measure to prevent the occurrence of erythema nodosum leprosum and/or persistent neuritis.
\end{abstract}

Keywords: Erythema nodosum; Leprosy; Neuritis; Retreatment

\section{INTRODUCTION}

Leprosy started to manifest in Brazil since the 16th Century, when it was brought by the first colonizers and slaves. ${ }^{1}$ Since then, this disease is considered a public health problem in the country. ${ }^{2}$

It is an infectious, contagious disease caused by Mycobacterium leprae that presents in approximately 4.68 to every 10,000 inhabitants. ${ }^{2}$ Its first symptoms and signs are dermato-neurological, and early diagnosis and treatment are important to prevent severe consequences to the patients and their family members due to the lesions that can physically incapacitate them.

Treatment employed for multibacillary leprosy is the multidrug therapy (MDT), performed by the assocation of rifampicin, dapsone and clofazimine. MDT leads to bacillary death enabling cure of the disease, preventing its transmission, thus breaking the epidemiologic chain. ${ }^{3}$
However, there might be cases of recurrence, even if the individual is considered cured after standard treatment. According to $\mathrm{WHO}$, the definition of recurrence is reappearance of the disease at any time after a complete course of MDT. ${ }^{4}$

The criteria for the suspicion and diagnosis of recurrence after discharge due to cure in the multibacillary form are the appearance of new skin lesions or worsening of the previous ones, new neurological disturbances with no response to the recommended course of corticosteroids, clinical picture suggestive of the disease, late reaction episodes (five years after discharge) and increase of $2+$ in the bacteriological index (BI) when compared to the one after discharge..$^{4-6}$

Currently, recurrence rates between $3 \%$ and $17 \%$ are seen, with the mean interval of 2 to 15 years after treatment. From 2004 to 2010 around 2,596 cases of recurrence worldwide were reported. In

Received on 02.12.2015.

Approved by the Advisory Board and accepted for publication on 30.01.2017.

Study conducted at Faculdade de Medicina de Botucatu - Universidade Estadual Paulista "Júlio de Mesquita Filho" (FMB-UNESP) - Botucatu (SP), Brazil. Financial support: None.

Conflict of interest: None.

Department of Dermatology and Radiotherapy, Faculdade de Medicina de Botucatu - Universidade Estadual Paulista "Júlio de Mesquita Filho" (UNESP) Botucatu (SP), Brazil.

Medical School Student - Universidade Estadual Paulista “Júlio de Mesquita Filho" (UNESP) - Botucatu (SP), Brazil.

Department of Biostatistics, Instituto de Biociências de Botucatu - Universidade Estadual Paulista "Júlio de Mesquita Filho" (UNESP) - Botucatu (SP), Brazil.

MAILING ADDRESS:

Joel Carlos Lastória

E-mail: lastoria@fmb.unesp.br

(C)2018 by Anais Brasileiros de Dermatologia

(cc) BY-NC 
Brazil, only in 2009, 1,483 leprosy recurrences were seen, representing a $3.9 \%$ increase of cases in that period. ${ }^{7}$

Irregular administration of MDT, insufficient treatment and the emergence of resistance to the specific treatment drugs, among other factors, are related to the occurrence of leprosy recurrence. ${ }^{5}$ In these cases, if recurrence is confirmed, the treatment should be repeated in its entirety. However, it is very difficult to establish if it is disease recurrence or reinfection.

Erythema nodosum leprosum (ENL) or type 2 reaction is an acute inflammatory process that occurs before, during or after leprosy treatment, frequently disrupting the chronic course of $M$. leprae infection. ENL can be considered an important cause for morbidity in leprosy patients, leading to neural injuries, paralysis and deformities. ${ }^{8-11}$

After treatment, many patients continue to have episodes of ENL, being the persistence of dead bacilli with antigenic properties implicated, what continues to trigger these episodes. ${ }^{2}$ This is so because multibacillary patients cannot eliminate them, therefore, they maintain their antigenicity. ${ }^{12,13}$

Nonetheless, these continuous episodes of ENL can also mean that, although without typical clinical signs of recurrence, in some cases they could be caused by the persistence of solid bacilli that are able to multiply. ${ }^{7}$

Therefore, according to this possibility and with all difficulties in comparison, such individuals could be considered with a possible recurrence and have the indication for a new treatment. ${ }^{2,4,5}$

The objective of this study was to evaluate patients with multibacillary leprosy that performed treatment with the recommended course of MDT but developed or continued to present ENL and/or neuritis 3-5 years after treatment, being thus considered as possible cases of recurrence and retreated.

\section{METHODS}

One hundred and twenty-two patients with ENL from 1999 to 2011 were seen at the Outpatient Clinic of the Hospital das Clínicas, Faculdade de Medicina de Botucatu, in Botucatu, São Paulo. Of those, 37 had an episode after the treatment and of those, 31 were assessed, of both genders and any age, who had multibacillary leprosy and continued to present type 2 reaction 3-5 years after standard MDT, from 2012 to 2015. They came referred from different health units or by self-referral.

The retreated patients were assessed according to:

- clinical picture;

- bacilloscopy and assessment of bacillary viability;

- occurrence or not of reaction episodes of ENL and/or neuritis.

Bacilloscopic tests were performed at Instituto Lauro de Souza Lima, in Bauru, São Paulo.

The patients who fulfilled the criteria for retreatment and that finished it were observed regarding the above-mentioned aspects during the consultations at the outpatient clinic.

In the case of persistent reaction episodes after treatment, these were classified in mild, moderate and severe. ${ }^{14}$ They are classified as mild when there are less than 10 nodules per body segment, with little pain and absent or mild systemic signs; moderate when there are 10 to 20 nodules per body segment and more than one of them is painful; fever below $38.4^{\circ} \mathrm{C}$, mild systemic symptoms with local and/or regional enlarged lymph node; and severe when there are more than 20 nodules per body segment, painful without touch, that can become confluent and ulcerate; fever above $38.5^{\circ} \mathrm{C}$, worsening of the general health status, chills, anorexia, fatigue, arthralgia, and the appearance of local and regional lymph nodes. ${ }^{14}$

This study was submitted to and approved by the Committee of Ethics in Research, with approval under the number 22183113.3.0000.5411. All patients analyzed signed a consent form.

Statistics was performed using the Goodman test for contrasts in multinomial proportions. ${ }^{15}$

\section{RESULTS}

Thirty-one patients who fulfilled the study criteria were evaluated, represented in graph 1.

According to what we see in graph 1, 29 patients (93.54\%) finished retreatment $(\mathrm{p}<0.001)$, and two $(6.45 \%)$ have not finished it yet, but continue to be seen. (Graph 1). Thus, we considered a sample of 29 patients.

In graph 2 the results achieved with retreatment can be seen.

Of the 29 patients who finished the retreatment, 27 (93.10\%) had complete resolution of ENL and/or neuritis, with a follow up between eight months to five years, while two (6.89\%) did not achieve resolution, and this result was considered very significant $(p<0.001)$. These two $(6.89 \%)$ patients who did not improve are taking thalidomide $(100 \mathrm{mg} /$ day), and are under control.

In graph 3 the results according to the reasons for retreatment and the resolution of the clinical picture are displayed.

Regarding the reason for retreatment, we observed that in $14(48.27 \%)$ patients it was because of recurrent ENL, in $10(34.38 \%)$, for having so many ENL episodes with neuritis and in five (17.24\%), due to difficult-to-control neuritis ( $p<0.05)$. Therefore, in total, there were 24 patients with ENL. Of the patients that retreated because of recurrent episodes of ENL, only two (8.33\%) did not get any response. All the patients $(100 \%)$ who reported difficult-to-control neuritis had a response with resolution of the clinical picture, including those who had that in association to ENL (Graph 3).

In graph 4 the results of the bacilloscopy are shown, and in graph 5, the morphological index (MI).

Bacilloscopy from all patients were collected before retreat-

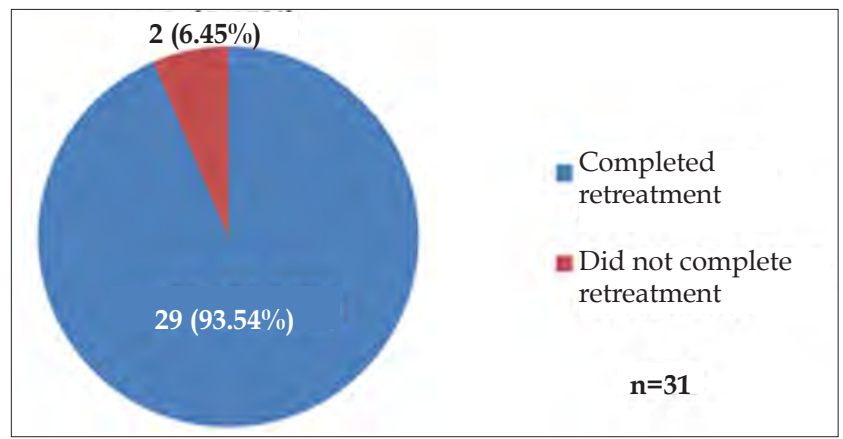

GraPh 1: Patient sample 
ment but, for different reasons, we obtained results of only 17 of them and, among these, 11 (64.7\%) were strongly positive, above $3+$, and six $(35.3 \%)$ were negative $(\mathrm{p}>0.05)$.

Of the 17 bacilloscopic tests performed, 11 were positive and, among these, six (54.5\%) had a positive morphological index and five $(45.5 \%)$ had a negative MI $(\mathrm{p}>0.05)$.

\section{DISCUSSION}

In this study we tried to evaluate patients with multibacillary leprosy who developed or maintained reaction episodes of ENL and/or neuritis 3-5 years after finishing treatment. Although there is considerable difficulty in considering these cases as recurrences, reinfection or resistance, we considered them as possible disease recurrences likely due to insufficient treatment, that is, the 12 doses of the medication might not have been enough for the cure. Therefore, they underwent a new treatment or retreatment, as suggested by the Ministry of Health. 2,16 These patients had episodes of ENL or neuritis every time thalidomide or corticosteroids were discontinued. They had no clinical signs of disease or activity.

Lastória et al. ${ }^{6}$ observed that around $20 \%$ of patients had a positive morphological index on the bacilloscopy after the WHO recommended 12-dose treatment, but that disappeared when treatment was continued for 24 doses. In view of this, the authors highlight the importance of obtaining the BI with the MI after the 12-dose treatment. With the evaluation of the MI before starting a new treatment or retreatment, it was seen that it was positive in six patients (54.5\%), and according to Lastória et al., the treatment could

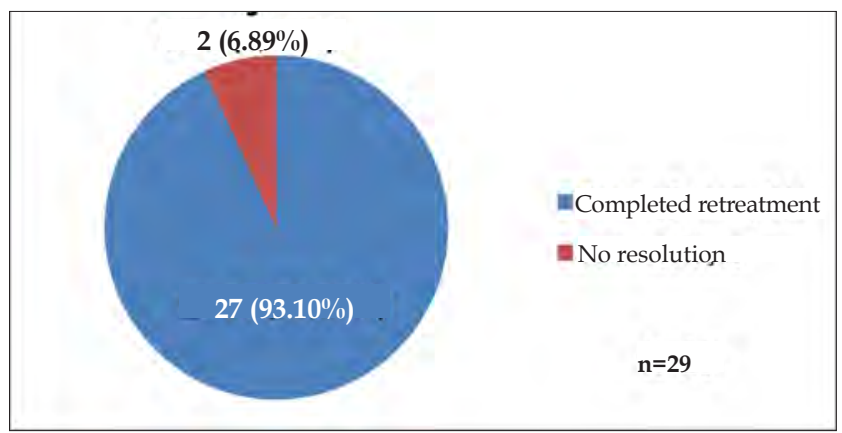

GrAPH 2: Retreatment results of the patients

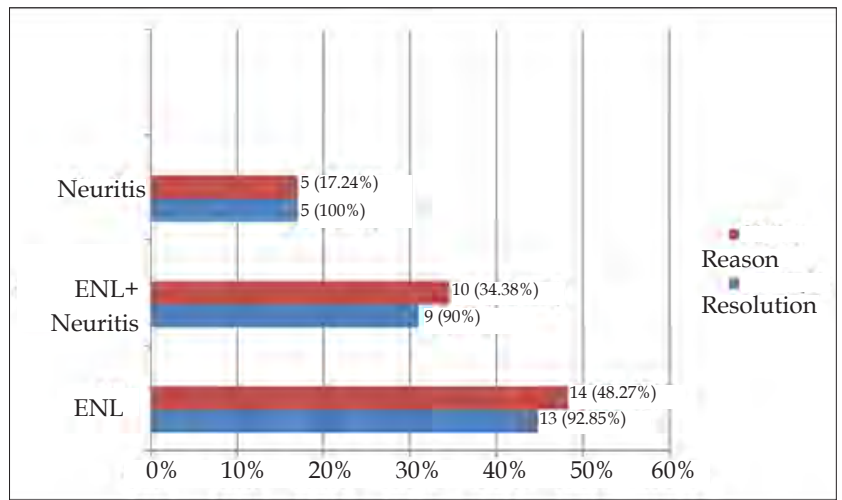

GRAPH 3: Demonstration of results according to the reason for retreatment have been extended to 24 doses, as mentioned above. Evidently, bacilloscopy can fail for different reasons, but has some significance when it is positive. Finding solid bacilli is still controversial regarding their viability, but it is a fact that should not be ignored.

The objective of this study was to retreat patients with episodes of ENL and/or neuritis. The simple occurrence of reaction episodes can lead to important neural damage and their reoccurrence can lead to even more severe damage, which may even be irreversible. Besides, many times the patients with this condition do not believe in the cure of the disease. Therefore, controlling these episodes is extremely important for the patient, and represents not only the resolution of the clinical picture, but also the belief that the disease can be cured.

In this respect, Putinatti et al. presented data related to the use of thalidomide as a way to control these episodes and prevent new ones. ${ }^{14}$ According to the recommendation of the Ministry of Health, ${ }^{2}$ patients with repeat difficult-to-treat episodes could be part of a group considered as recurrence and would deserve another treatment.

Considering the results obtained above, we could observe that $27(93.10 \%)$ patients stopped developing ENL-type reaction episodes or neuritis, while only two $(6.89 \%)$ continued to present them but were controlled with thalidomide, and when this was discontinued, the episodes were considered to be mild when they reappeared. However, even though the assessment for drug resistance was not performed in these patients, both had bacillary growth and were considered resistant to rifampicin, which was posteriorly replaced by ofloxacin. These patients have not developed reaction

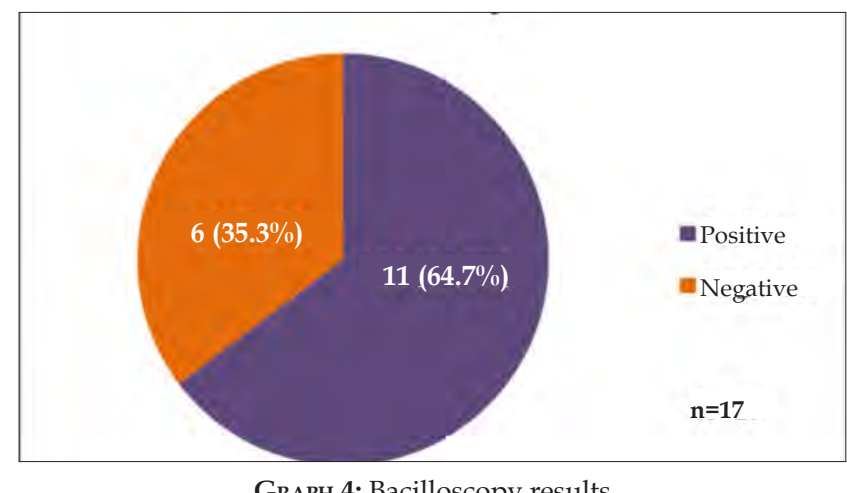

GrAPH 4: Bacilloscopy results

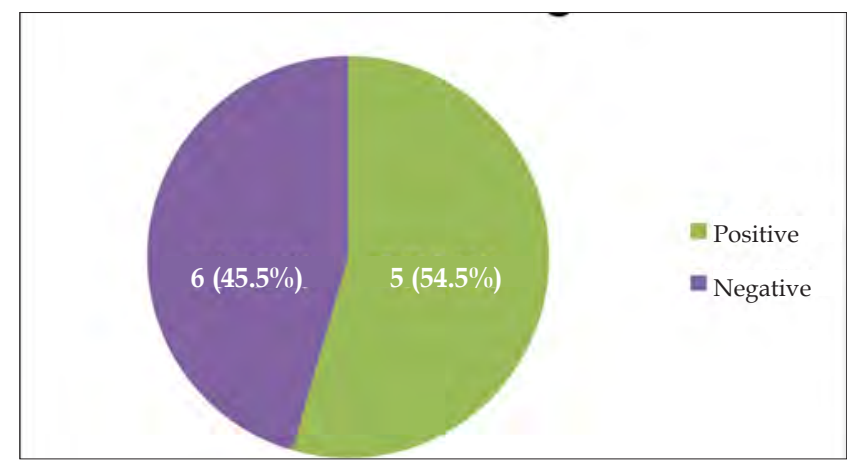

GrAPH 5: Morphological index results 
episodes till present.

One of the patients, who did not complete the treatment, developed a flu-like syndrome after starting the medications, which led to substitution of rifampicin by ofloxacin. This patient did not develop new lesions after the sixth monthly dose of treatment and is under follow-up until the treatment is finished. The other patient did not complete the treatment during the study and is under follow-up.

Therefore, in total, even not finishing the retreatment, three patients did not have reaction episodes anymore.

Although there is a possibility of a retreatment according to the recommendation of the Ministry of Health, there are no reports of studies in the literature that confirm its benefit. However, some colleagues use this strategy but do not show any results in the literature. We also considered that the Informative Note n. ${ }^{\circ}$ 51, 2015 , of the Ministry of Health, ${ }^{16}$ supports this study, since it started and ended a long time before this publication.

Something else to be considered is that there is a rate of about $20 \%$ of noncompliance to leprosy treatment. ${ }^{16}$ In this study, despite the patients having been submitted to a new MDT (12 doses of treatment), all were compliant.

Thus, be it for insufficient treatment or any other reason such as drug resistance, these patients can be considered as possible cases of disease recurrence and can maintain the epidemiological chain of transmission. Regarding resistance, we can consider that it was not the case in these patients, since they responded to the new treatment with no occurrence of reaction episodes.

With these results, the authors suggest that the continuity of appearance of reactions or neuritis after a specified time from the recommended treatment could be considered as possible cases of re-

\section{REFERENCES}

1. Miranda RN, Melo SMAL. Origem da hanseníase no Brasil/ Hansen's origin in Brazil. Rev Med Paraná. 1995;52:21-3.

2. Brasil. Ministério da Saúde. Secretaria de Políticas de Saúde. Departamento de Atenção Básica. Guia para o Controle da Hanseníase. Brasília: Ministério da Saúde; 2002.

3. Penna GO. Tratamento da hanseníase com poliquimioterapia padrão OMS com duração fixa. Rev Soc Bras Med. Trop. 1995;28:167-8.

4. World Health Organization. Guideline for Global surveillance of Drug Resistance in Leprosy. WHO Regional Office for South-East Asia; 2009

5. Brito MFM, Ximenes RAA, Gallo MEN. Retreatment of leprosy relapse. An Bras Dermatol. 2005;80:255-60.

6. Lastória JC, Putinatti MSMA, Diório SM, Trino LM, Padovani CR. Índices baciloscópicos e morfológico na hanseníase após doze doses do esquema poliquimioterápico (PQT/OMS). Hansen Int. 2006:31:15-21.

7. Ferreira SMB, Ignotti E, Gamba MA. Fatores associados à recidiva em hanseníase em Mato Grosso. Rev. Saúde Pública. 2011;45:756-64.

8. Guerra JG, Penna GO, Castro LCM, Martelli CMT, Stefani MMA. Erythema Nodosum Leprosum: clinical and therapeutic up-date. An Bras Dermatol. 2002:77:389-407. currence and deserve a new treatment. In this study, we considered 3-5 years or more. Retreatment proved to be effective considering the disappearance of the reactions, the main causes for neural damages in $93.1 \%$ of cases and these patients started to believe that they are really cured.

Thalidomide was discontinued in these patients as the ENL episodes were controlled, and it is important to highlight that they had a follow-up of 8 months to 5 years, and showed no signs of ENL and/or neuritis, and there was no more need for treatment for the reactions or for the neuritis.

Therefore, the authors suggest that after the first episode of ENL, thalidomide $100 \mathrm{mg}$ / day be maintained for about six months, with the possibility of disappearance. ${ }^{14}$ On the other hand, we also suggest that whenever possible, a BI with a MI be performed, what could indicate ongoing treatment in the cases where the latter is positive or in the cases where there is an increase in the BI. ${ }^{6,16}$

If these procedures are not feasible and the reaction episodes continue, a new treatment can be instituted. And, in these cases, it would be interesting to collect samples for the assessment of the ability of bacillary multiplication and drug resistance.

Our sample can be considered small, but it has importance, and other studies are needed. Patients in this study will continue follow-up.

\section{CONCLUSION}

Retreatment can prevent the occurrence of persistent reaction episodes and/or neuritis after MDT. $\square$

\section{AKNOWLEDGEMENTS}

FAPESP - Scholarship for scientific initiation to one of the authors (Thaís Sampaio Corrêa de Almeida).
9. Lastoria JC, Parise-Fortes MR, Putinatti MSMA, Macharelli CA, Padovan CR. Erythema nodosum leprosum in patients with multibacillary leprosy. In: 18. International Leprosy Congress, 2013, Bruxelas. FINAL Programme, Boock of abstrcts, p.122, p. 268

10. Lastória JC, Abreu MA. Leprosy: Review of the epidemiological, clinical, and etiopathogenic aspects.. An Bras Dermatol. 2014:89:205-18.

11. Talhari S, Penha GO, Gonçalves HS. Hanseníase. Rio de Janeiro: Ed. Di Livros Ltda.; 2015. Capítulo 4, Reações Hansênicas; p. 45-60.

12. Kahawita IP, Walker Stephen L, Lockwood Diana NJ. Leprosy type 1 reactions and erythema nodosum leprosum. An Bras Dermatol. 2008;83:75-82.

13. Lastoria JC. A reação de Mitsuda seriada na identificação das formas reacionais tuberculoide e dimorfa da hanseníase [tese]. Botucatu (SP): Universidade Estadual Paulista "Júlio de Mesquita Filho"; 1990. 115 p.

14. Putinatti MSMA. Prevenção da repetição de episódios de reação tipo 2 da hanseníase com o uso da talidomida na dose de 100mg/dia [tese]. Botucatu (SP): Universidade Estadual Paulista "Júlio de Mesquita Filho"; 2011.

15. Goodman LA. On simultaneous confidence intervals for multinomial proportions. Technometrics. 1965;7:247-54.

16. Brasil. Ministério da Saúde. Secretaria de Vigilância em Saúde. Departamento de Vigilância das Doenças Transmissíveis. Nota informativa N. ${ }^{\circ}$ 51, de 2015 CGHDE/ DEVIT/SVS/MS. Nota informativa sobre recidiva e resistência medicamentosa na hanseníase. Brasília: Ministério da Saúde; 2015.

How to cite this article: Lastória JC, Almeida TSC, Putinatti MSMA, Padovani CR. Effectiveness of the retreatment of patients with multibacillary leprosy and episodes of erythema nodosum leprosum and/or persistent neuritis: a single-center experience. An Bras Dermatol. 2018;93(2):181-4 